\title{
Individual differences in normal body temperature: longitudinal big data analysis of patient records
}

\author{
Ziad Obermeyer, ${ }^{1,2}$ Jasmeet K Samra, ${ }^{1}$ Sendhil Mullainathan ${ }^{3}$
}

${ }^{1}$ Department of Emergency Medicine, Brigham and

Women's Hospital, Boston, MA, USA

${ }^{2}$ Department of Emergency Medicine and Health Care

Policy, Harvard Medical School, Boston, MA, USA

${ }^{3}$ Department of Economics, Harvard University, Boston,

MA, USA

Correspondence to:

Z Obermeyer

zobermeyer@bwh.harvard.edu

Additional material is published online only. To view please visit the journal online.

Cite this as: BMJ 2017;359:j5468 http://dx.doi.org/10.1136/bmj.j5468

Accepted: 23 November 2017

\author{
ABSTRACT \\ OBJECTIVE \\ To estimate individual level body temperature and \\ to correlate it with other measures of physiology and \\ health.
}

DESIGN

Observational cohort study.

SETTING

Outpatient clinics of a large academic hospital, 2009-14.

\section{PARTICIPANTS}

35488 patients who neither received a diagnosis for infections nor were prescribed antibiotics, in whom temperature was expected to be within normal limits.

\section{MAIN OUTCOME MEASURES}

Baseline temperatures at individual level, estimated using random effects regression and controlling for ambient conditions at the time of measurement, body site, and time factors. Baseline temperatures were correlated with demographics, medical comorbidities, vital signs, and subsequent one year mortality.

RESULTS

In a diverse cohort of 35488 patients (mean age 52.9 years, $64 \%$ women, $41 \%$ non-white race) with 243506 temperature measurements, mean temperature was $36.6^{\circ} \mathrm{C}\left(95 \%\right.$ range $35.7-37.3^{\circ} \mathrm{C}, 99 \%$ range 35.3 $37.7^{\circ} \mathrm{C}$ ). Several demographic factors were linked to individual level temperature, with older people the coolest $\left(-0.021^{\circ} \mathrm{C}\right.$ for every decade, $\left.\mathrm{P}<0.001\right)$ and African-American women the hottest (versus white men: $\left.0.052^{\circ} \mathrm{C}, \mathrm{P}<0.001\right)$. Several comorbidities were linked to lower temperature (eg, hypothyroidism: $-0.013^{\circ} \mathrm{C}, \mathrm{P}=0.01$ ) or higher temperature (eg, cancer: $0.020, P<0.001)$, as were physiological measurements (eg, body mass index: 0.002 per $\mathrm{m} / \mathrm{kg}^{2}, \mathrm{P}<0.001$ ). Overall, measured factors collectively explained only

\section{WHAT IS ALREADY KNOWN ON THIS TOPIC}

A long tradition of research on human core body temperature, starting in the 19th century, has focused on establishing average temperature in a population Temperature is known to be influenced by many factors that differ widely across patients (eg, age and circadian, metabolic, and ovulatory cycles) raising the possibility that individual baseline body temperatures might vary systematically

\section{WHAT THIS STUDY ADDS}

Individual baseline temperatures are correlated with specific demographic factors, with older people the coldest and African-American women the hottest

Particular medical conditions were also statistically significantly linked to lower or higher temperature, as were physiological measurements, but these factors explained only $8.2 \%$ of variation in individual baseline temperatures

The remaining unexplained variation was a large and significant predictor of subsequent mortality, nearly $8.4 \%$ higher mortality for a 1 SD increase in temperature
$8.2 \%$ of individual temperature variation. Despite this, unexplained temperature variation was a significant predictor of subsequent mortality: controlling for all measured factors, an increase of $0.149^{\circ} \mathrm{C}(1 \mathrm{SD}$ of individual temperature in the data) was linked to $8.4 \%$ higher one year mortality $(P=0.014)$.

\section{CONCLUSIONS}

Individuals' baseline temperatures showed meaningful variation that was not due solely to measurement error or environmental factors. Baseline temperatures correlated with demographics, comorbid conditions, and physiology, but these factors explained only a small part of individual temperature variation. Unexplained variation in baseline temperature, however, strongly predicted mortality.

\section{Introduction}

Have you ever felt cold, or warm, in a room where everyone else felt comfortable? This common experience about room temperature has some interesting lessons for body temperature and how we measure it. To know how warm or cold someone feels, we would not look at room temperature alone. Married couples sitting next to each other in the same room routinely disagree about whether to turn the heat up or down. Individuals have different baseline propensities to feel hot or cold-at any given absolute room temperature.

Yet doctors have forgotten this lesson when measuring core body temperature. We would not use absolute room temperature to infer perceived warmth, but we do use absolute body temperature to infer fever.

In medical school, students are taught that humans have a core body temperature as a species, not as individuals. When clinicians take patients' temperatures in the clinic or hospital, they compare the measurements with the population average. Deviations from this single number help in the diagnosis of acute pathological states, from infections to thyroid disorders.

Why should someone's physiological state be compared with an absolute standard temperature? Body temperature deviations, after all, can have their roots in individual physiology, such as age ${ }^{12}$ and circadian, ${ }^{3}$ metabolic, ${ }^{4}$ and ovulatory cycles. ${ }^{5}$ These factors vary dramatically across individuals, raising the possibility that individuals have baseline temperatures that differ systematically from the population average. The same temperature that is normal for one person might be dangerously high for another.

Historically, the use of a population average was partly a data problem: estimating each individual's baseline body temperature would have been challenging. Any credible effort would need to tease apart individual baseline temperatures from other 
sources of variation in measured temperatures: ambient conditions when temperature is taken, ${ }^{6}$ differences in technique, ${ }^{78}$ and random error due to intrinsic variability in the measurement process itself. ${ }^{89}$ Distinguishing signal from noise under these conditions would require large amounts of data: both large numbers of patients and multiple temperature measurements for each patient.

The modern electronic health record stores rich physiological data, including temperature, on large numbers of patients, and many have noted its potential to generate new clinical knowledge. ${ }^{10}{ }^{11}$ We used these data to deal with random errors in individual temperature measurements, by applying statistical techniques that find signal and minimize noise across multiple temperature measurements, taken in a variety of outpatient settings and for a large number of patients. To deal with the many factors known to affect temperature measurements, we used rich contextual data to control for conditions at the time of measurement: ambient temperature, humidity, time of day, date, and body site of measurement. This allowed us to estimate stable baseline temperatures for every patient in our large and diverse sample, as opposed to population averages. We then explored links between individual temperature and a range of other variables: demographics; physiological measures, including vital signs; and mortality.

Individual differences in body temperature might be meaningful in two ways. Firstly, their very existence could open new insights into human physiology and links between body temperature, metabolism, and longevity. ${ }^{12-14}$ Secondly, individualized "precision temperatures" could allow doctors to tailor testing and treatment decisions to patients' physiology. At a minimum, they might change one familiar part of the doctor-patient conversation: the eye-rolling that sometimes ensues when patients report that a given temperature, although normal, is "high for me."

\section{Methods}

Until recently, large scale databases of temperature measurements were scarce: with some notable exceptions, ${ }^{15} 16$ most studies of body temperature in humans date from 1950 or before ${ }^{17}$ and have important limitations. Temperatures were measured at varying times of day and in different seasons, using unspecified instruments. ${ }^{17}$ Details regarding enrollment procedures were often absent, but-particularly in older studiesthere was little apparent concern about achieving a diverse sample of patients for race, sex, and comorbid conditions. ${ }^{17}$ Lack of longitudinal data meant that temperature measurements could not be correlated to subsequent outcomes. ${ }^{15-17}$ Perhaps most importantly, albeit with some exceptions, ${ }^{15} 18$ sample sizes were small-often in the 10 s to 100 s of patients. ${ }^{1617}$

\section{Sample}

We used a dataset of electronic health records from a large US based academic hospital. The dataset was assembled in two steps: firstly, we identified patients to be included in the cohort-those with one or more visits to the hospital's emergency and outpatient departments during 2010-12; and, secondly, we obtained data on each of these patient's outpatient visits from 2009-14, consisting of visits to clinics during which a temperature was measured (Welch Allyn SureTemp Plus digital thermometers were present in most examination rooms).

Since we were interested in individual estimates of normal body temperature in adults, we focused on routine visits during which temperature was expected to be within normal limits. We did not include emergency department visits, during which acute physiological disturbances may affect measured temperatures. We excluded patients aged less than 18 years and those seen on weekends or outside business hours (7 am-6 pm), to avoid selecting patients seen for non-routine problems; those with implausible recorded temperatures $\left(<32^{\circ} \mathrm{C}\right.$ and $>45^{\circ} \mathrm{C} ; 0.04 \%$ of the total sample); and those visiting clinics for infections, to remove the effect of infection related disturbances in body temperature. We thus excluded visits with ICD-9 (international classification of diseases, ninth revision) codes for infectious diseases, and visits with antibiotics prescribed in the week after the visit (see supplement eTable 1 for cohort construction). Our final sample accounted for roughly $3-5 \%$ of the hospital's annual load of outpatient visits.

\section{Statistical analysis}

\section{Estimating individual baseline temperatures}

In the included sample of routine outpatient visits, we used ordinary least squares regression to model measured visit level temperature as a function of external conditions (ie, ambient temperature and dew point, drawn from National Oceanographic and Atmospheric Administration data ${ }^{19}$ ), body site (eg, oral, axillary), and time of measurement (hour, day, month, and year).

To estimate baseline temperatures, we modeled individual patients' deviations from the population mean, controlling for the selected factors. We used fixed effects to ensure that individual temperature effects were approximately normally distributed (see supplement eFigure 1), then we re-estimated the model using random effects. We chose random effects because even in the presence of measurement error they are consistent and efficient estimators of variance. ${ }^{20} 21$ These steps allowed us to estimate individual temperature effects as well as features of the population level distribution, such as the variance of individual effects. Using individual level effects necessarily restricted the sample to patients with at least two measured temperatures over the study period. We omitted time invariant attributes of patients (eg, sex, race) since these cannot be estimated alongside individual level effects. Standard errors were clustered at patient level.

We correlated the resulting individual temperature random effects with other variables of interest in the electronic health record, in three groups: demographics, including age, sex, and race; comorbidities, defined 
using ICD-9 codes over the year before visits, following usual practice ${ }^{22}$; and physiological measurements (pulse, systolic and diastolic blood pressure, body mass index), using average values over the period spanning from first to last included visit date for each patient-this mirrored the period over which individual level effects were estimated in our dataset. Since we were exploring a range of correlations, we adjusted $\mathrm{P}$ values for multiple hypothesis testing using the Holm sequential procedure. ${ }^{23}$ Alternative methods of adjustment $\mathrm{t}^{2425}$ are provided in supplement eTable 3 (results were substantively unchanged).

\section{Relation between individual temperature effects and mortality}

Finally, we explored the relation between individual temperature and mortality, using linkage to state social security data. To accurately calculate one year mortality, we addressed a source of bias in these longitudinal cohort data: patients were sampled and included in the cohort because of encounters over 2010-12, up until which they were necessarily alive. Likewise, patients were followed until their last temperature measurement, as late as 2014, at which time they were also alive by construction. Since our primary interest was the correlation between mortality and routine temperature measurements, we calculated mortality in the year after each patient's last temperature measurement, excluding those whose 2010-12 sampling event occurred after the last temperature measurement ( $16 \%$ of the sample). We then estimated the relation between one year mortality and individual temperature effects by logistic regression, controlling for demographics, comorbidities, and physiological measures. As the hospital is a referral center serving patients from the local community and further awaywho require specialized care for complex, serious illnesses with high mortality-we also controlled for log distance between patients' home zip code and hospital zip code.

\section{Statistical packages}

All analyses were performed in STATA (version 14.0) and R (version 3.2.3; Foundation for Statistical Computing).

\section{Patient involvement}

No patients were involved in setting the research question or the outcome measures, nor were they involved in developing plans for design or implementation of the study. No patients were asked to advise on interpretation or writing up of results. There are no plans to disseminate the results of the research to study participants or the relevant patient community.

\section{Results}

Of 374306 patients with temperature measurements at outpatient visits, we excluded 130800 (largely because of infection diagnoses or antibiotic prescriptions; see supplement eTable 1), leaving 243506 visits (18\% of all outpatient visits meeting the other inclusion criteria). Table 1 shows demographics, physiological measurements, comorbidities, and one year mortality. The mean age at time of the visit was 52.9 years, $64 \%$ of patients were women, and $41 \%$ were of nonwhite race (including 16\% black or African-American patients, $17 \%$ Hispanic patients). The most common primary diagnoses at included outpatient visits were osteoarthritis (5.9\%), back pain (4.9\%), and routine evaluation and examination (4.5\%). The clinics most commonly visited were orthopedics (10\%) and internal medicine (hospital based clinic: $7.8 \%$, community clinic: $5.7 \%$ ). One year mortality in this sample of patients receiving care at a tertiary referral hospital was $6.2 \%$, considerably higher than in the general population $(<1 \%$ in a similar age range).

The mean measured temperature was $36.6^{\circ} \mathrm{C}(95 \%$ confidence interval $36.6^{\circ} \mathrm{C}$ to $36.6^{\circ} \mathrm{C}$ ). Each patient had a median 5 (interquartile range 3-9) temperature measurements over a median of $2.1(0.8-3.8)$ years, and $19 \%$ had more than 10 measurements.

\section{Summary statistics on temperature}

- Mean $36.6^{\circ} \mathrm{C}\left(95 \%\right.$ range $35.7-37.3^{\circ} \mathrm{C}$; $99 \%$ range $\left.35.3-37.7^{\circ} \mathrm{C}\right)$

- Measurements at different sites (versus oral): temporal: $-0.03^{\circ} \mathrm{C}$; tympanic: $-0.06^{\circ} \mathrm{C}$; axillary: $-0.26^{\circ} \mathrm{C}$

Figure 1 shows the correlation of temporal and environmental factors to measured body temperature, estimated by using random effects regression. Temperature measurements were largely oral $(88.2 \%$ oral, 3.5\% temporal, $3.0 \%$ tympanic, $0.1 \%$ axillary, $5.2 \%$ not recorded), and temporal, tympanic, and axillary temperatures were significantly lower than oral temperatures (by $-0.03^{\circ} \mathrm{C},-0.06^{\circ} \mathrm{C}$, and $-0.27^{\circ} \mathrm{C}$, respectively; all $\left.\mathrm{P}<0.001\right)$. We observed diurnal variation in temperature by hour, with a peak at $4 \mathrm{pm}\left(0.03^{\circ} \mathrm{C} v 12 \mathrm{pm}, \mathrm{P}<0.001\right)$. Higher ambient temperature and dew point were both linked to higher body temperature. Month effects worked to offset these effects-that is, at the same ambient temperature and dew point, summer months were linked to lower body temperature and winter months to higher body temperature. On a median temperature day in our dataset $\left(12.2^{\circ} \mathrm{C}\right)$, body temperature was on average $0.08^{\circ} \mathrm{C}$ lower in July than in February, presumably reflecting the effect of compensatory physiological mechanisms (eg, evaporative cooling, vasoconstriction) by season. Supplement eTable 2 presents the full coefficients from the model.

The standard deviation for random effects from this model, denoted as individual baseline temperatures, was 0.15 , with $95 \%$ range (ie, 2.5-97.5th centile range) $0.60^{\circ} \mathrm{C}\left(-0.33-0.27^{\circ} \mathrm{C}\right)$. In comparison, the standard deviation for raw measured body temperature was 0.42 , with $95 \%$ range $1.67^{\circ} \mathrm{C}$ (after subtracting the mean, for comparability: $-0.93-0.74^{\circ} \mathrm{C}$ ).

Table 2 shows demographics, vital signs, and comorbidities by fifth of individual baseline temperature, along with regression coefficients of 


\begin{tabular}{|c|c|}
\hline Characteristics & Estimates $(n=243506)$ \\
\hline No of patients & 35488 \\
\hline \multicolumn{2}{|l|}{ Most common reason for visit*: } \\
\hline Osteoarthritis and osteoarthrosis & $8397(5.9)$ \\
\hline Back condition & $7094(4.9)$ \\
\hline Examination and evaluation & $6473(4.5)$ \\
\hline Hypertension & $5962(4.2)$ \\
\hline Joint pain & $4844(3.4)$ \\
\hline \multicolumn{2}{|l|}{ Clinic visited most often: } \\
\hline Orthopedics & $25463(10.0)$ \\
\hline Internal medicine (hospital) & $19011(7.8)$ \\
\hline Internal medicine (community) & $13894(5.7)$ \\
\hline Arthritis center & $12078(5.0)$ \\
\hline Women's health center & $10950(4.5)$ \\
\hline Mean (interquartile range) aget (years) & $53(21-85)$ \\
\hline Men & $12656(36)$ \\
\hline Women & $22832(64)$ \\
\hline \multicolumn{2}{|l|}{ Race: } \\
\hline White or European & $20930(59)$ \\
\hline Black or African-American & $5756(16)$ \\
\hline Hispanic & $6169(17)$ \\
\hline Other & $2633(7.4)$ \\
\hline Median (interquartile range) miles to hospital & $8.4(4.2-25.4)$ \\
\hline Mean (interquartile range) comorbidity index scoreł & $1.33(-1-8)$ \\
\hline \multicolumn{2}{|l|}{ Individual comorbidities: } \\
\hline Hypertension§ & $12759(36)$ \\
\hline Tumorq & $7607(21)$ \\
\hline Arrhythmia§ & $7438(21)$ \\
\hline Pulmonary diseaseी & $5497(15)$ \\
\hline Uncomplicated diabetes§ & $5256(15)$ \\
\hline Depression§ & $4314(12)$ \\
\hline Anemia§ & $3970(11)$ \\
\hline Obesity§ & $3585(10)$ \\
\hline Electrolytes§ & $3381(9.5)$ \\
\hline Hypothyroidism§ & $2781(7.8)$ \\
\hline Congestive heart failuref & $2485(7.0)$ \\
\hline Metastatic cancer $\mathbb{9}$ & $2413(6.8)$ \\
\hline Kidney disease§ & $2330(6.6)$ \\
\hline Psychosis§ & $2160(6.1)$ \\
\hline Cerebrovascular diseaseी & $2075(5.8)$ \\
\hline Neurodegenerative disease $\S$ & $1819(5.1)$ \\
\hline One year mortality** & $1679(6.2)$ \\
\hline \multicolumn{2}{|c|}{$\begin{array}{l}{ }^{*} \text { ICD-9-CM codes grouped into clinical classification software }{ }^{37} \text { categories. } \\
\text { †Age at time of visit } \\
\text { †Comorbidities based on Gagne et al } 2011,{ }^{22} \text { which combines Elixhauser and Romano indices; comorbidities } \\
\text { present in }<5 \% \text { of patients were omitted from table. } \\
\text { \$Elixhauser comorbidity. } \\
\text { १Romano comorbidity. } \\
{ }^{\star *} \text { Mortality calculated for year after last temperature measurement (see Methods). }\end{array}$} \\
\hline
\end{tabular}

baseline temperatures on the variable. Baseline temperatures declined with age $\left(-0.02^{\circ} \mathrm{C}\right.$ every decade, $\mathrm{P}<0.001)$. African-American women had the highest temperature $\left(0.052^{\circ} \mathrm{C}\right.$ higher than white men, $\left.\mathrm{P}<0.001\right)$. Baseline temperature also varied significantly as a function of comorbid conditions. Cancer was linked to higher temperature $\left(0.02^{\circ} \mathrm{C}, \mathrm{P}<0.001\right)$, whereas hypothyroidism was linked to lower temperature $\left(-0.01^{\circ} \mathrm{C}, \mathrm{P}=0.01\right.$; the relation was linear for mean thyroid stimulating hormone level over the span of the data (see supplement eFigure 2A). The total number of comorbidities was not statistically significantly linked to baseline temperature over and above all individual included comorbidities.

Table 2 shows the relation between individual baseline temperatures and average physiological
Effect

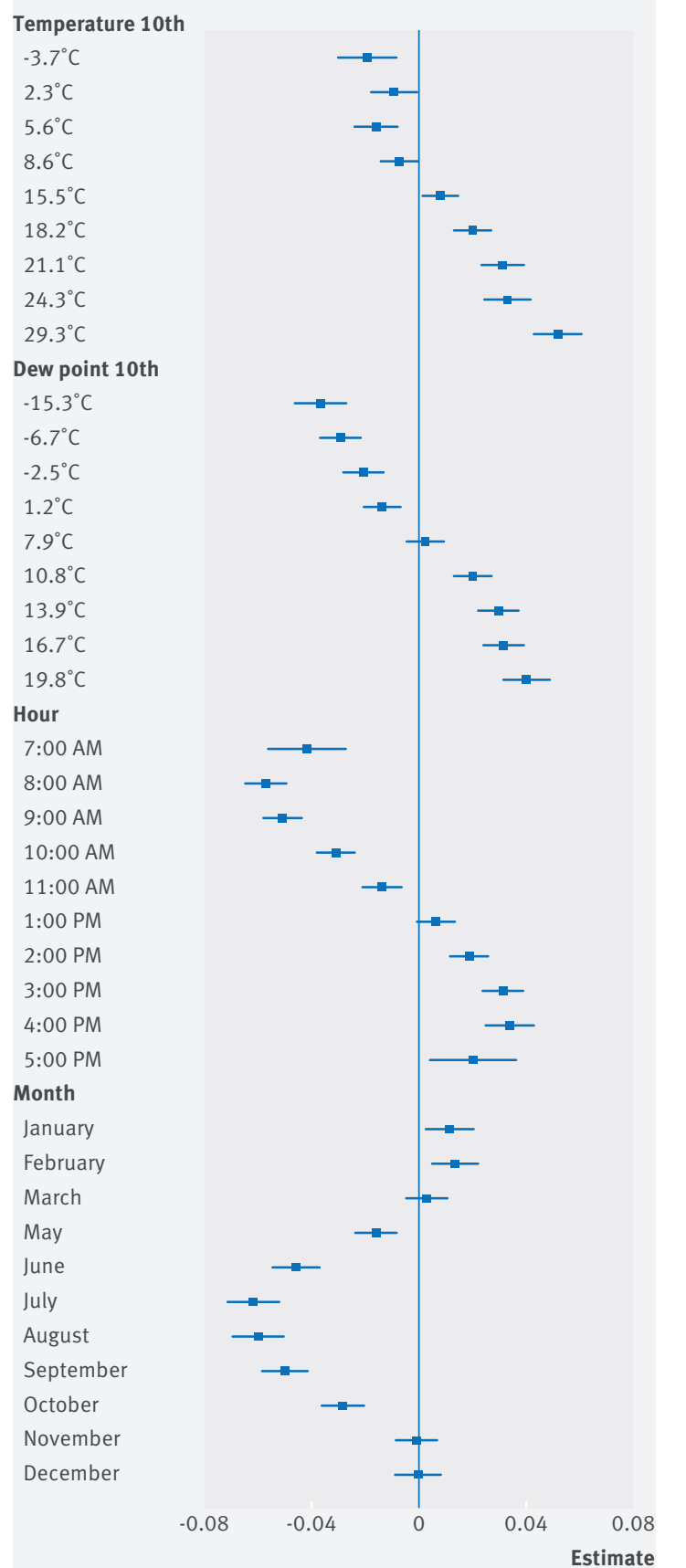

Fig 1 | Relation of temporal and environmental factors to measured body temperature. Coefficients estimated by random effects regression are shown for ambient temperature, dew point, hour, and month, compared with reference categories: median temperature 10th $\left(12.2^{\circ} \mathrm{C}\right)$, median dew point 10 th $\left(4.7^{\circ} \mathrm{C}\right), 12 \mathrm{pm}$, and April, respectively

measurements over the study period. Controlling for demographic factors and comorbidities, higher temperatures were linked to increased body mass index $\left(0.002^{\circ} \mathrm{C}\right.$ per $\left.\mathrm{m} / \mathrm{kg}^{2}, \mathrm{P}<0.001\right)$. Higher temperature was also linked to higher pulse $\left(4.0 \times 10^{-5 \circ} \mathrm{C}\right.$ per beats per minute, $\left.\mathrm{P}=0.17\right)$ and increased diastolic blood pressure $\left(1.2 \times 10^{-4} \mathrm{o} \mathrm{C}\right.$ per $\mathrm{mm} \mathrm{Hg}, \mathrm{P}=0.01)$. Figure 2 shows mean vital signs 


\begin{tabular}{|c|c|c|c|c|}
\hline \multirow[b]{2}{*}{ Predictor variables included in model } & \multicolumn{4}{|c|}{ Regression coefficients modeling individual temperature } \\
\hline & Coefficient & SE & Pvalue & Adjusted P value* \\
\hline \multicolumn{5}{|l|}{ Demographics: } \\
\hline Aget & -0.021 & 0.001 & $<0.001$ & $<0.001$ \\
\hline White women & 0.023 & 0.003 & $<0.001$ & $<0.001$ \\
\hline \multicolumn{5}{|l|}{ White men } \\
\hline Black women & 0.052 & 0.004 & $<0.001$ & $<0.001$ \\
\hline Black men & 0.015 & 0.006 & 0.01 & 0.12 \\
\hline Hispanic women & 0.030 & 0.004 & $<0.001$ & $<0.001$ \\
\hline Hispanic men & 0.019 & 0.006 & 0.001 & 0.01 \\
\hline \multicolumn{5}{|l|}{ Comorbidities:: } \\
\hline Comorbidity sum score§ & 0.002 & 0.002 & 0.27 & 1 \\
\hline Hypertension 9 & $-1.7 \mathrm{e}-4$ & 0.003 & 0.96 & 1 \\
\hline Tumorn & 0.020 & 0.003 & $<0.001$ & $<0.001$ \\
\hline Arrhythmiaq & -0.002 & 0.004 & 0.62 & 1 \\
\hline Pulmonary disease ${ }^{\star \star}$ & -0.012 & 0.004 & 0.001 & 0.01 \\
\hline Uncomplicated diabetes & 0.009 & 0.003 & 0.005 & 0.08 \\
\hline Depression & 0.008 & 0.003 & 0.01 & 0.17 \\
\hline Anemiaף & 0.005 & 0.004 & 0.24 & 1 \\
\hline Obesity & -0.011 & 0.004 & 0.004 & 0.06 \\
\hline Electrolytes & -0.003 & 0.004 & 0.46 & 1 \\
\hline Hypothyroidism I & -0.013 & 0.004 & 0.001 & 0.01 \\
\hline Congestive heart failure ${ }^{\star \star}$ & -0.027 & 0.006 & $<0.001$ & $<0.001$ \\
\hline Metastatic cancer ${ }^{\star \star}$ & 0.004 & 0.010 & 0.68 & 1 \\
\hline Kidney diseaseी & -0.025 & 0.006 & $<0.001$ & $<0.001$ \\
\hline Psychosis & -0.005 & 0.005 & 0.35 & 1 \\
\hline Cerebrovascular** & 0.003 & 0.004 & 0.53 & 1 \\
\hline Neurodegenerative & -0.003 & 0.005 & 0.53 & 1 \\
\hline \multicolumn{5}{|l|}{ Physiological measures: } \\
\hline Body mass index $\left(\mathrm{kg} / \mathrm{m}^{2}\right)$ & 0.002 & $1.8 \mathrm{e}-4$ & $<0.001$ & $<0.001$ \\
\hline Pulse (beats per min) & $4.0 e-5$ & $1.6 \mathrm{e}-5$ & 0.01 & 0.17 \\
\hline Systolic blood pressure $(\mathrm{mm} \mathrm{Hg})$ & $1.8 \mathrm{e}-6$ & $4.0 e-6$ & 0.65 & 1 \\
\hline Diastolic blood pressure $(\mathrm{mm} \mathrm{Hg})$ & $1.2 \mathrm{e}-4$ & $3.5 e-5$ & 0.001 & 0.01 \\
\hline Respiratory rate (breaths per min) & $-2.5 e-5$ & $1.1 \mathrm{e}-4$ & 0.82 & 1 \\
\hline \multicolumn{5}{|c|}{ 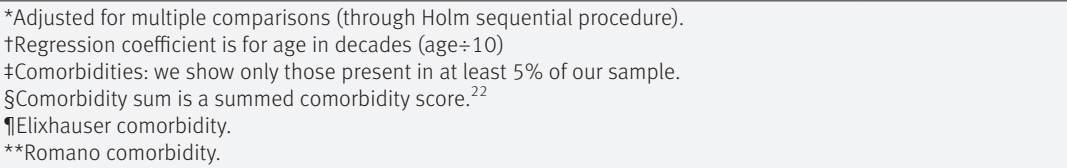 } \\
\hline
\end{tabular}

over the study period and their relation to baseline temperatures by sex.

Despite the many statistically significant relations identified between individual baseline temperatures and demographics, comorbidities, and physiological measures, these factors collectively accounted for only $8.2 \%$ of variation (adjusted $\mathrm{R}^{2}$ ) in temperature. Residual variation was greater for women than for men (residual sum of squares: $283 \mathrm{v} 170$ ), raising the possibility that at least part of the residual difference was driven by hormonal cycles (not measured). However, most variation in baseline temperatures remained unexplained by commonly measured health variables in both sexes.

Table 3 shows the relation between individual baseline temperature and mortality. Controlling for age, sex, race, vital signs, and comorbidities, a $1^{\circ} \mathrm{C}$ increase in temperature translated into 3.5\% higher mortality $(\mathrm{P}=0.014)$. For example, a $1 \mathrm{SD}$ increase in temperature $\left(0.15^{\circ} \mathrm{C}\right)$ would translate into a $0.52 \%$ absolute increase in one year mortality. Compared with a mean mortality of $6.2 \%$ in our sample, this represented an $8.4 \%$ relative increase in mortality risk.

\section{Discussion}

To our knowledge, this is the first attempt to demonstrate meaningful variation in individual body temperature, separately from random measurement error and the influence of external factors, and to correlate them to a range of patient factors and outcomes in a diverse patient population.

These results illustrate a way in which "big data" can serve to generate new medical knowledge. Here we used these data not to answer a causal question (eg, to discover side effects of drugs) or to predict an outcome (eg, to create an early warning system for a given condition), but to discover previously unsuspected and potentially important patterns in human physiology. It is unlikely that any one practitioner could have noticed these patterns, despite their fairly large magnitude connections with mortality. Rather, large datasets and statistical methods are needed to bring out these patterns from the empirical record.

Our most noteworthy result was the connection between temperature and mortality. This fits with a larger body of research showing that reduction in body temperature increases longevity and delays aging in a range of (ectothermic) experimental models, including Drosophila and Caenorhabditis elegans, ${ }^{26}$ as well as transgenic (homeothermic) mice engineered to have lower temperatures. ${ }^{12}$ This observation raises a set of questions that may be worth answering through further research. What is the biological basis for an individual's baseline temperature? And how might these factors teach us more about subtle but important physiological patterns that might lead to good or poor outcomes? Two sets of results from our analysis were suggestive along these lines.

Firstly, individual temperatures were highly correlated with measured patient characteristics, particularly those related to metabolism and obesity. These differences may have their roots in obvious thermodynamic factors: bodies with larger mass dissipate heat less rapidly, leading to higher temperatures. Fat (which is correlated with mass) could also act as an insulator, independent of mass, leading to higher heat retention in people with more fat. Other explanations, however, are also plausible. It is well known that caloric restriction through fasting leads to down-regulation of temperature, presumably to conserve energy ${ }^{27}$; indeed, reduced temperature is now considered a biomarker for caloric restriction. ${ }^{13}{ }^{14}$ Although there are few trials of caloric supplementation, the existing literature suggests that individuals vary widely in their ability to dissipate excess energy from overfeeding. ${ }^{28}$ Given the strong links between resting metabolic rate and body temperature, ${ }^{4}$ it is possible that higher resting body temperature could be a response serving to dissipate excess energy from caloric intake. We found that a raised temperature correlated with both body mass index and activation of the sympathetic nervous system (ie, increased pulse rate and diastolic blood pressure). Thus temperature could be another variable in the cluster of traits linking obesity and activation 

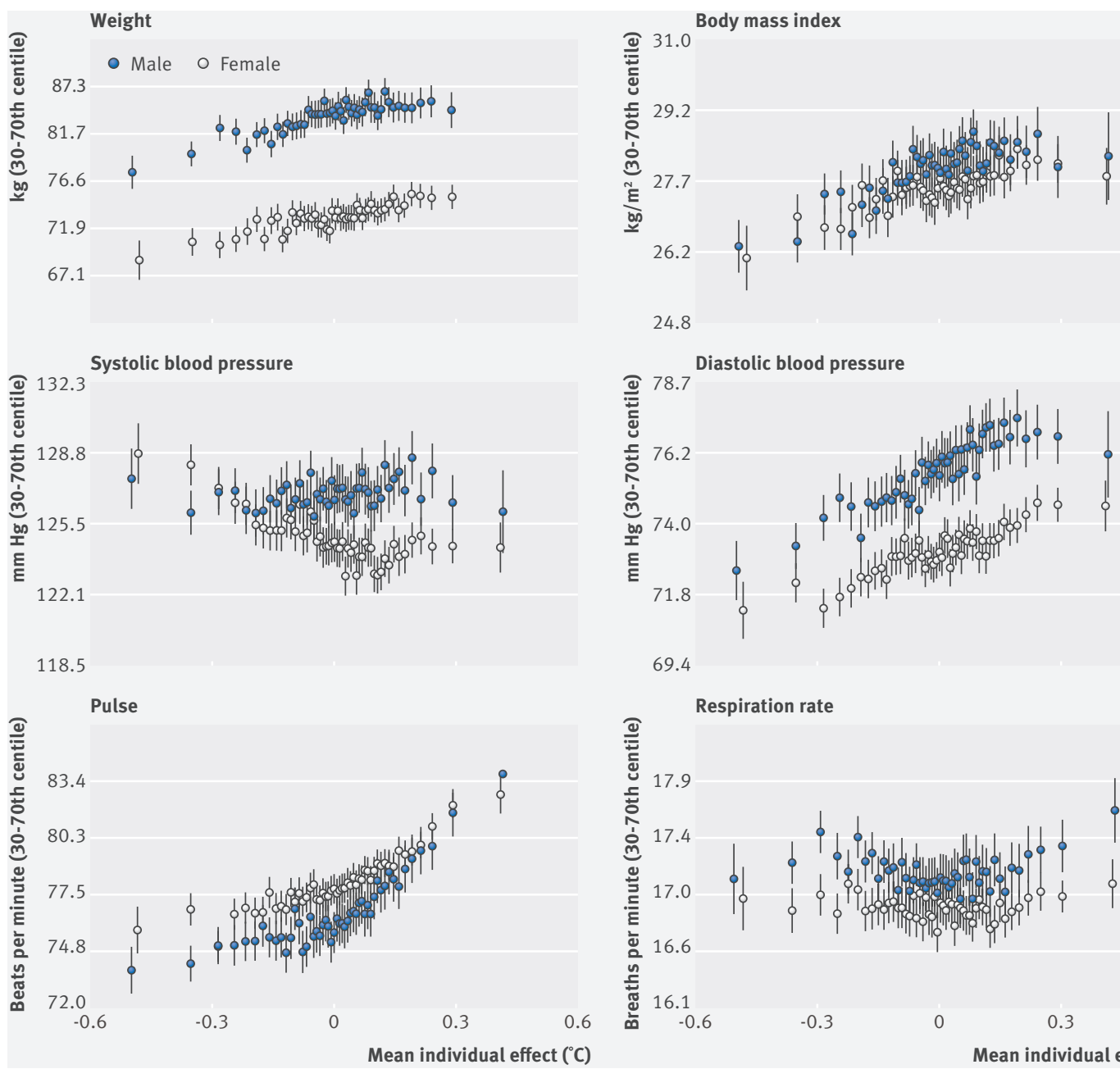

$$
\begin{array}{r}
69.4 \\
\text { Respiration rate }
\end{array}
$$

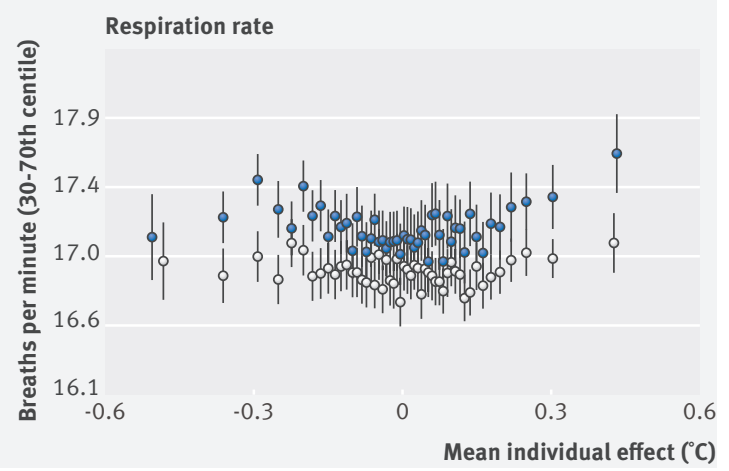

Fig 2 | Physiological measurements and relation to temperature effects, by sex. Dots represent centiles of individual temperature effect and vertical bar $95 \%$ confidence intervals

of the sympathetic nervous system. ${ }^{29-31}$ Interestingly, while our temperature effects were estimated over longer periods, some small studies have found that hypothermia is linked to increased mortality for acute events (eg, in hip fractures), ${ }^{32}$ potentially implying a different physiology in short term versus long term temperature regulation.

Secondly, we found a large correlation between individual baseline temperature and mortality that was not explained by measured patient characteristics. What factors might this temperature variation be picking up on that confer an $8.4 \%$ mortality disadvantage? It is tempting to speculate. We did identify a correlation between diagnosed cancers and temperature. This has been noted in the literature previously, either because of the direct metabolic demands of the cancer itself, ${ }^{33}$ or because of the body's immune response. ${ }^{34}$ Subclinical infections or rheumatological diseases could exert a similar effect. If higher temperature reflected undiagnosed cancers or other illnesses, this would generate the correlation we observed between the unexplained component of temperature variation and subsequent mortality from these same illnesses. Another potential explanation is that higher temperature reflected a pro-inflammatory milieu; however, we found no clear connection between individual temperature and the inflammatory marker reactive protein (see supplement eFigure $2 \mathrm{~b}$ ). Ultimately, further study is required. We could imagine studies that estimated individual temperature effects using similar methods, then subjected those with higher temperatures to additional diagnostic studies to identify undiagnosed illnesses.

The finding that measured temperature was, other things being equal, lower in hot months and higher in cold months may reflect engagement of well known compensatory adaptations (eg, plasma volume, evaporative cooling, vasoconstriction, shivering) to temperatures experienced over longer periods, as opposed to the short term direct effects of higher or lower temperature. ${ }^{35}$ Related recent work has shown, for example, that drinking warm beverages on warm days results in heat loss from increased sweat output. ${ }^{36}$

Finally, our estimate of population mean temperature differed from other studies-for example, it was lower than in a sample of primarily young, healthy participants, ${ }^{16}$ and higher than in a population 


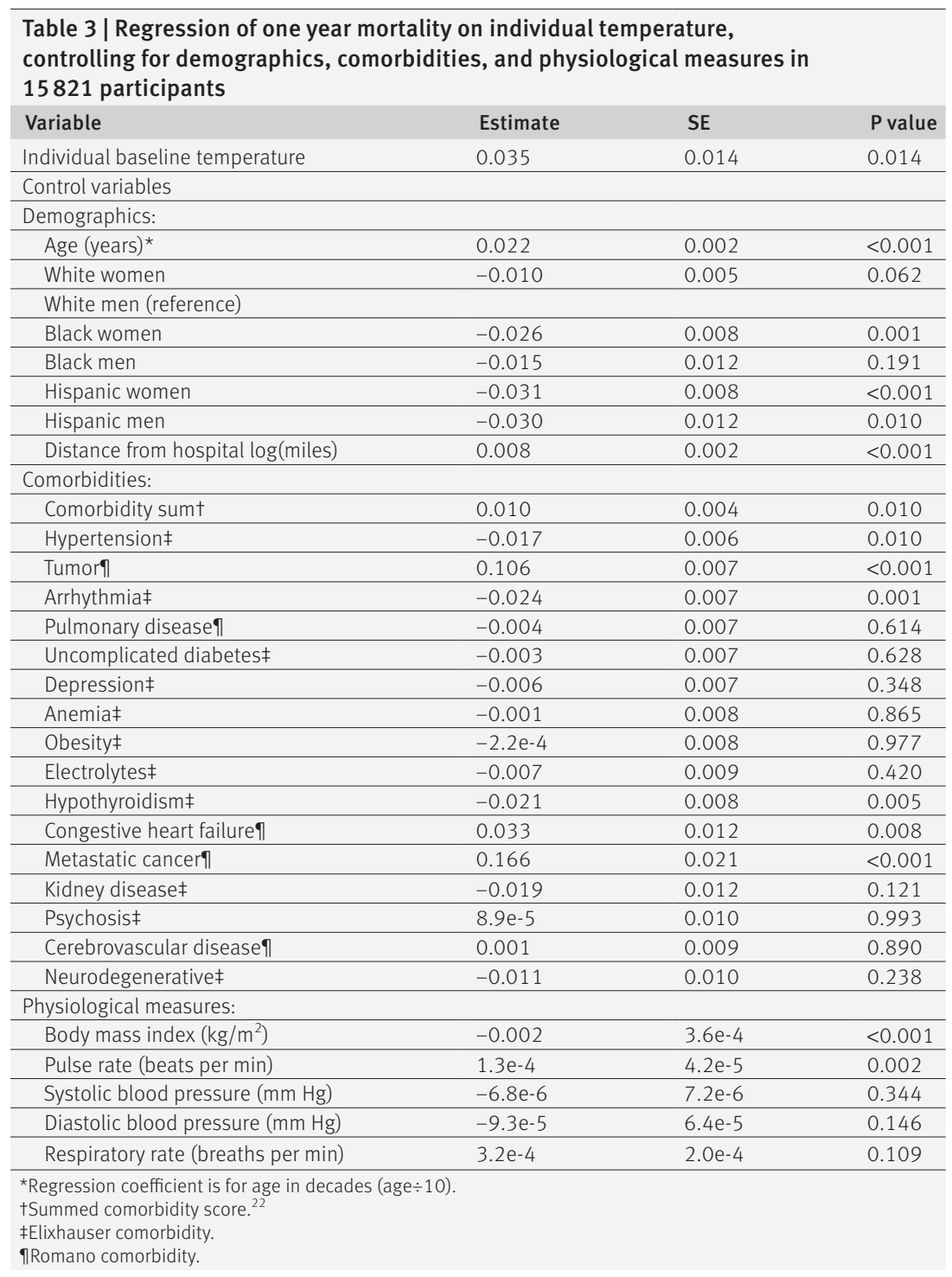

of older adults seen in healthcare settings. ${ }^{15}$ One potential advantage of our approach is that it adjusted for environmental and temporal factors at the time of measurement, which was not possible in other studies. Although this might enhance the generalizability of our estimate, it would be difficult for any one study of core temperature to ensure that estimates are valid for an entire species. However, it may help with clinical decision making for populations seeking healthcare in similar settings.

\section{Limitations of this study}

Our study had several limitations. We considered patients at one academic center and measured temperature using similar equipment, which can have correlated errors in measurement. Our methods were designed to estimate robust deviations in individual temperature separately from measurement error but might not generalize to other equipment, although we would guess that stringent Food and Drug Administration standards for clinical electronic thermometers offer some guarantees that the relative magnitude of effects should be similar. Our data came from one climate zone. Although we controlled for the substantial variation in environmental conditions within this zone, temperature and compensatory mechanisms may vary across climactic zones. We excluded patients with infection and those prescribed antibiotics, but it is possible that some patients had infections that were undiagnosed and untreated by their physicians. However, since this would have to be a consistent finding over multiple visits for the same patients, and since most infections are by contrast transient, this is unlikely to have affected our estimated correlation between individual baseline temperature and mortality. We sampled patients based on visits to a hospital emergency department and clinics. This resulted in an ethnically and medically diverse sample over multiple years of data, but it also selected a sicker set of patients, with a higher comorbidity burden and mortality than the general population. An advantage is that our sample was representative of the population of patients using healthcare today.

\section{Conclusions}

We found that individuals have body temperature baselines that correlate with a range of demographic factors, comorbid conditions, and physiological measurements. Since the unexplained variation in temperature is large and correlates with mortality, it may be an interesting and important area for further study.

We thank Philip Mackowiak for comments on an early draft of this manuscript.

Contributors: ZO and SM designed the study and wrote the manuscript. ZO obtained funding. JKS and ZO analyzed the data. All authors had full access to all of the data (including statistical reports and tables) in the study and can take responsibility for the integrity of the data and the accuracy of the data analysis. ZO acts as guarantor. Funding: This study was supported by a grant from the office of the director of the National Institutes of Health (DP5 OD012161) to ZO. This research was independent from funders. The funder had no role in the study design; in the collection, analysis, and interpretation of data; in the writing of the report; or in the decision to submit the article for publication.

Competing interests: All authors have completed the ICMJE uniform disclosure form at www.icmje.org/coi_disclosure.pdf and declare: no financial relationships with any organizations that might have an interest in the submitted work in the previous three years; no other relationships or activities that could appear to have influenced the submitted work.

Ethical approval: This study was approved by the institutional review boards of Partners HealthCare, the parent organization of the hospita where the research was conducted.

\section{Data sharing: No additional data available.}

Transparency: The lead author (ZO) affirms that the manuscript is an honest, accurate, and transparent account of the study being reported; that no important aspects of the study have been omitted; and that any discrepancies from the study as planned have been explained.

This is an Open Access article distributed in accordance with the Creative Commons Attribution Non Commercial (CC BY-NC 4.0) license, which permits others to distribute, remix, adapt, build upon this work non-commercially, and license their derivative works on different terms, provided the original work is properly cited and the use is noncommercial. See: http://creativecommons.org/licenses/by-nc/4.0/. 1 Güneş UY, Zaybak A. Does the body temperature change in older
people? J Clin Nurs 2008;17:2284-7. doi:10.1111/j.13652702.2007.02272.x 
2 Castle SC, Norman DC, Yeh M, Miller D, Yoshikawa TT. Fever response in elderly nursing home residents: are the older truly colder? J Am Geriatr Soc 1991;39:853-7. doi:10.1111/j.1532-5415.1991. tb04450.x

3 Refinetti R, Menaker M. The circadian rhythm of body temperature. Physiol Behav 1992;51:613-37. doi:10.1016/ 0031-9384(92)90188-8

4 Landsberg L, Young JB, Leonard WR, Linsenmeier RA, Turek FW. Is obesity associated with lower body temperatures? Core temperature: a forgotten variable in energy balance. Metabolism 2009;58:871-6. doi:10.1016/j.metabol.2009.02.017

5 Moghissi KS, Syner FN, Evans TN. A composite picture of the menstrual cycle. Am J Obstet Gynecol 1972;114:405-18. doi:10.1016/0002-9378(72)90617-5

6 Halonen JI, Zanobetti A, Sparrow D, Vokonas PS, Schwartz J. Relationship between outdoor temperature and blood pressure. Occup Environ Med 2011;68:296-301. doi:10.1136/ oem.2010.056507

7 Sund-Levander M, Forsberg C, Wahren LK. Normal oral, rectal, tympanic and axillary body temperature in adult men and women: a systematic literature review. Scand J Caring Sci 2002;16:122-8. doi:10.1046/j.1471-6712.2002.00069.x

8 Erickson R. Oral temperature differences in relation to thermometer and technique. Nurs Res 1980;29:157-64 doi:10.1097/00006199-198005000-00004

9 Burnham RS, McKinley RS, Vincent DD. Three types of skinsurface thermometers: a comparison of reliability, validity, and responsiveness. Am J Phys Med Rehabil 2006;85:553-8. doi:10.1097/01.phm.0000223232.32653.7f

10 Topol E). Transforming medicine via digital innovation. Sci Trans Med 2010;2:16cm4. doi:10.1126/scitranslmed.3000484

11 Murdoch TB, Detsky AS. The inevitable application of big data to health care. JAMA 2013;309:1351-2. doi:10.1001/jama.2013.393

12 Conti B, Sanchez-Alavez M, Winsky-Sommerer R. Transgenic mice with a reduced core body temperature have an increased life span. Science 2006:314:825-8 doi:10.1126/science.1132191

13 Roth GS, Lane MA, Ingram DK. Biomarkers of caloric restriction may predict longevity in humans. Science 2002;297:811. doi:10.1126/ science. 1071851

14 Heilbronn LK, de Jonge L, Frisard MI. Pennington CALERIE Team. Effect of 6-month calorie restriction on biomarkers of longevity, metabolic adaptation, and oxidative stress in overweight individuals: a randomized controlled trial. JAMA 2006;295:1539-48. doi:10.1001/ jama.295.13.1539

15 Waalen J, Buxbaum JN. Is older colder or colder older? The association of age with body temperature in 18,630 individuals. Gerontol A Biol Sci Med Sci 2011;66:487-92. doi:10.1093/gerona/ glr001

16 Mackowiak PA, Wasserman SS, Levine MM. A critical appraisal of $98.6^{\circ} \mathrm{F}$, the upper limit of the normal body temperature, and other legacies of Carl Reinhold August Wunderlich. JAMA 1992;268 1578-80. doi:10.1001/jama.1992.03490120092034

17 Horvath SM, Menduke H, Piersol GM. Oral and rectal temperatures of man. J Am Med Assoc 1950;144:1562-5. doi:10.1001/ jama.1950.62920180006007

18 Wunderlich CA. On the temperature in diseases: a manual of medical thermometry. New Sydenham Society; 1871. https://books.google. $\mathrm{com} /$ books? hl=en\&lr=\&id=3-wHAAAAIAAJ\&oi=fnd\&pg=PA19\&dq= wunderlich+temperature $\&$ ots $=9$ atUIZjAlx \&sig=qsNSqTYmhYcZHG zvNaB-8l-Cmk
19 National Oceanographic and Atmospheric Administration. NCEP Meteorological Assimilation Data Ingest System (MADIS). https:// madis.ncep.noaa.gov/ Accessed September 18, 2017.

20 Gardiner JC, Luo Z, Roman LA. Fixed effects, random effects and GEE: what are the differences? Stat Med 2009;28:221-39. doi:10.1002/ sim.3478

21 Wooldridge JM. Econometric analysis of cross section and panel data. MIT press; 2010. https://books.google.com/ books?hl=en\&lr=\&id=hSs3AgAAQBAJ\&oi=fnd\&pg=PP1\&dq= econometrics+wooldridge\&ots=VXLTsXYXQr\&sig=fVNIOkwnd6Z LROIp8nfTGXk1rA

22 Gagne JJ, Glynn RJ, Avorn J, Levin R, Schneeweiss S. A combined comorbidity score predicted mortality in elderly patients better than existing scores. J Clin Epidemiol 2011;64:749-59. doi:10.1016/j. jclinepi.2010.10.004

23 Holm S. A simple sequentially rejective multiple test procedure. Scand J Stat 1979;6:65-70

24 Bland JM, Altman DG. Multiple significance tests: the Bonferroni method. BMJ 1995;310:170. doi:10.1136/bmj.310.6973.170

25 Benjamini Y, Hochberg Y. Controlling the false discovery rate: a practical and powerful approach to multiple testing. J. R. Stat Soc Ser B Methodol1995:289-300.

26 Conti B. Considerations on temperature, longevity and aging. Cell $\mathrm{Mol}$ Life Sci 2008;65:1626-30. doi:10.1007/s00018-008-7536-1

27 Keys A. The biology of human starvation. University of Minnesota Press, 1950.

28 Bouchard C, Tremblay A, Després J-P. The response to long-term overfeeding in identical twins. N Engl J Med 1990;322:1477-82 doi:10.1056/NEJM199005243222101

29 Grassi G, Seravalle G, Cattaneo BM. Sympathetic activation in obese normotensive subjects. Hypertension 1995;25:560-3.

30 Troisi RJ, Weiss ST, Parker DR, Sparrow D, Young JB, Landsberg L. Relation of obesity and diet to sympathetic nervous system activity. Hypertension 1991;17:669-77.

31 Scherrer U, Randin D, Tappy L, Vollenweider P, Jéquier E, Nicod P. Body fat and sympathetic nerve activity in healthy subjects. Circulation 1994;89:2634-40. doi:10.1161/01.CIR.89.6.2634

32 Faizi M, Farrier AJ, Venkatesan M. Is body temperature an independent predictor of mortality in hip fracture patients? Injury 2014;45:1942-5. doi:10.1016/j.injury.2014.09.024

33 Lawson RN, Chughtai MS. Breast cancer and body temperature. Can Med Assoc J 1963;88:68-70.

34 Repasky EA, Evans SS, Dewhirst MW. Temperature matters! And why it should matter to tumor immunologists. Cancer Immunol Res 2013;1:210-6. doi:10.1158/2326-6066.CIR-13-0118

35 Bass DE, Kleeman CR, Quinn M, Henschel A, Hegnauer AH. Mechanisms of acclimatization to heat in man. Medicine (Baltimore) 1955;34:323-80. doi:10.1097/00005792195509000-00002

36 Bain AR, Lesperance NC, Jay O. Body heat storage during physical activity is lower with hot fluid ingestion under conditions that permit full evaporation. Acta Physiol (Oxf) 2012;206:98-108. doi:10.1111/ j.1748-1716.2012.02452x

37 Agency for Healthcare Research and Quality. Clinical classifications software (CCS) for ICD-9-CM. www Hcup-Us Ahrq Govtoolssoftwareccsccs Jsp, 2011: 11.

Supplemental information: eTables 1-3 and eFigures 1 and 2 